$422 \mathrm{Mr}$. Wilde on the 'early History of aural Surgery, \&c.

practical judgments upon such subjects. In such inquiries speculation only leads to error. Facts and the aggregate testimony derived from the results obtained by the practice of medical men scattered over great space and much time, giving, with candour and fairness, the number of recoveries and deaths, can alone furnish the elements for sound and satisfactory conclusions.

ART. XVI.-Some Observations on the early History of aural Surgery, and the nosological Arrangement of Diseases of the Ear. By W. R. WILDE, M. R. I. A., Surgeon to St. Mark's Ophthalmic Hospital and Dispensary for Diseases of the Eye and Ear.

In the present day, when literature in every Protean shape and form has compassed the land, and knowledge may be truly said to run to and fro thronghout the earth; and when the polyglott cyclopædia of the press has outstripped in the race all other feats of human prowess of the nineteenth century, it might be deemed unnecessary to follow the old school system of detailing the early history of that particular branch of the healing art, or its elementary or collateral sciences, of which this essay treats, were it not that in an art but just emerging from the darkness, ignorance, empiricism, prejudice, and superstition, which is even yet the condition of aural medicine and surgery, its history not only becomes interesting, but practically instructire.

I might, with the generality of writers upon the history of medicine, commence with the times of Hippocrates, for he makes several allusions to the affections of the organs of hearing, not, however, as idiopathic forms of disease, but as symptomatic of other maladies of an acute and chronic nature; but it must be borne in mind that at that period of medical science (and, I regret to add, that it has in a great part descended to the present) the affections of the ear, whether functional or organic, were spoken of, lectured on, written of, and described, not according 
Mr. Wilde on the carly History of aural Surgery, \&c. 423

to the laws of pathology which regulate other diseases, but by a single symptom, that of deafness. "If," says Dr. Kramer, " by tumours behind the ears, to be dispersed by copious diarrhœa if they are not to prove fatal, we are to understand otitis interna and its terminations, and carious destruction of the mastoid process, as a result of the otitis interna; and if, further, I mention that the treatment of deafness (viz. as it occurs as a functional disorder only of the ear, without any perceptible external alteration of the organ) merely consists of not washing out the ear, but cleansing it with wool, dropping in oil, directing the patient to walk out, rise early, drink white wine, abstain from salads, and allowing him to eat bread, and such fish as inhabit rocky shores, I shall have collected all that is of most importance to give an idea of acoustic medicine at that time."

To Celsus, the successor of Hippocrates, we are indebted for the first acknowledgment of the specific or independent forms of aural disease-for having introduced the practice of ocular inspection of the anditory canal-and for some general rules for the treatment of the inflammatory affections of the organs of hearing ; but this advance in acoustic medicine, which we owe to Celsus, is more than counterbalanced by his introduction into practice of those stimulating nostrums which were then, and have been since, applied to the membrana tympani without discrimination and without mercy; and many of which are made use of in the present day. Galen followed in the track of his great predecessor, and although he advanced some. what in symtomatology, and although he was evidently better acquainted with the causes of the inflammatory diseases of the ear, yet he and his disciples so increased the number of remedial agents, which were applied to the external meatus, that we find aural medicine and surgery, toward the end of the fifteenth century, but a collection of bard names, and unconnected symptoms, the fanciful theories based on causes the most improbable, and a category of medical substances from the animal, mineral, and vegetable kingdoms, principally, however, 


\section{$424 \mathrm{Mr}$. Wilde on the early History of aural Surgery, \&c.}

composed of hot spices and stimulating applications, of which I may mention castor, ox-gall, garlic, frankincense, opium, nitre, alum, iron filings boiled on vinegar, hellebore, myrrh, turpentine, and many other such substances, each lauded by their respective admirers, and extolled as panaceas for deafness in all its numerous forms and modifications.

It would afford us neither literary interest nor practical utility, commensurate with the task, to detail the notions concerning the treatment and diseases of the ear, as they may be found scattered throughout the writings of Aurelianus, Paul of Agina, Razes, Serapion, Hali Abbas, Mesue, and Dioscorides, the works of the three latter of whom were translated into Grelic by several distinguished Irish physicians from the beginning of the fourteenth to the end of the sixteenth century.

At the conclusion of the fifteenth century the anatomy of the ear received a new impulse, and was raised to its proper footing by the investigations and discoveries of some of the most distinguished anatomists and physicians of that age, and in compliment to their labours it was, that the subsequent anatomists gave those parts names which we retain to the present day, as, the tube of Eustachius, the aquaduct of Fallopius, the liquor of Cotunnius, and the fissure of Casserius ; but although these distinguished men made the world better acquainted with the anatomy of the organ of hearing, and thus removed one of the greatest obstacles to the investigation of aural pathology, their successors in medicine advanced but little in the investigation and treatment of diseases of the ear.

The first special work upon the ear that $I$ have been able to discover is that of Heurnius Mercurialis, entitled, "De oculorum et aurium affectibus Prelectiones," and the first edition of which was published at Frankfort in $\mathbf{1 5 8 4 .}$

Mercurialis was chiefly a compilator from the works of the Greeks, Romans, and Arabians, and as an original investigator deserves no credit; but he collected all that was known and had been written before his day on aural disease; the little he did 
Mr. Wilde on the early History of aural Surgery, \&c. 425

add, was that of a few more nostrums, and therefore he may be consulted with advantage by those of the fraternity who still adhere to the good old rule of applying such remedies as hot onions in acute inflammations of the meatus or tympanum.

I must not omit to mention, as connected with aural pathology, that it was in this, the sixteenth century, that the attention of the philanthropist was first turned towards the lamentable condition of the deaf and dumb. Prior to that period, during those ages wont to be called enlightened, and in those countries styled civilized, and even refined, among the Egyptians, Greeks, Romans, and Hebrews, and even still in the Orient, the deaf mute was, and is, but little removed from the brute, and is often employed for the basest and most degrading offices, such as humanity in the present day, at least in this country, shudders at. Up to this period the deaf and dumb were not considered susceptible of improvement or instruction of any kind, and their very passions, unrestrained by any influence, human or divine, were frequently made to minister to the cruelty or sensuality of those around them.

How long this might have remained the stereotyped condition of these unhappy, isolated children of Adam, but for the fatherly affection of Joachim Pascha, the chaplain of Prince James the Second, of Brandenburgh, about the year 1560, it is difficult to say. This good and venerable man undertook, and succeeded in instructing his own mute daughter by means of a series of pictures. After him a Spanish Benedictine monk at Sahagan, in the kingdom of Leon, one Petro de Ponce, who died in 1584, taught the two sons of a Castilian nobleman and a young Arragonise to read and write with elegance, not only the language of their own country, but also the Latin tongue ; and it is also related by Ambrosio Morales, the historian of this distinguished and indefatigable man, that they could understand by sight the expressions of the lips; and likewise spoke as those do at present who have been taught in a modern deaf and dumb institution.

Having elsewhere enlarged upon this subject, I have made 
$426 \mathrm{Mr}$. Wilde on'the early History of aural Surgery, \&c.

this digression merely for the purpose of fixing the date of an interesting inquiry in aural pathology.

The first book that treated of our subject in the seventeenth century was a posthumous Latin work of Jos Heurnius, on the diseases of the organs of hearing, published by his son, the celebrated Otho Heurnius, in 1602. Lincke, however, says that he was but a compiler.

Heretofore the treatment of aural diseases consisted, for the most part, in medical agents and empirical nostrums ; but at the beginning of that century (that is in 1646), the principles of surgery were brought to bear upon this class of affections by the master hand of Fabricius von Hilden. His observations on the extraction of foreign bodies, on polypus, and other affections of the external auditory conduit, are well worthy of perusal ; and to him is generally ascribed the invention of the first speculum auris, as well as the first ear instruments on record. This speculum was formed on the principle of the common forceps-like instrument now in general use.

This is the instrument, or one similarly constructed, which tradition has handed down to the present day, as having been used by Fabricius; but from the following passage in a still older writer, Peter de la Cerlata, "per inspectionem ad solem trahendo aurem et ampliando cum speculo aut alio instrumento," I am led to believe that means were employed before his time for examining the external auditory passages. Instruments of this kind, and for this purpose, having been once recognized and employed by practitioners, have since been variously modified, according to the ingenuity of the inventor;-yet their first introduction into practice decidedly formed an epoch in aural surgery. Fabricius's observations, and the description of his instruments, will be found in his "Opera Omnia" published in 1646.

After the days of this great surgeon, the next work of any merit that appeared in connexion with aural medicine, was published by a Genevese anatomist, Theophilus Bonet; his observations, as they are set forth in his great work, the "Sepulcre- 
Mr. Wilde on the early History of aural Surgery, \&c. 427 tum," or "Chirurgica Practica," were chiefly confined to the pathology of the ear from dissection; but in a practical point of view he advanced little beyond the limits attained by his predecessors. A few years later, toward the conclusion of the serenteenth century, aural surgery received a new impulse from the talents and laborious investigations of the distinguished French anatomist, Du Verney. Of late it has become the fashion to decry the labours of this great man-in my humble judgment unjustly-for he was far in advance of his time, and although the pathological is not as voluminous, nor perhaps as accurate as the anatomical part of his writings on the organ of hearing, still he was a lucid painter, and a graphic describer of disease. He was the first person who arranged the diseases of the ear according to the anatomical structures affected, as, into those of the outer ear and meatus, those of the middle ear or tympanum, and those of the internal ear or labyrinth. From the times of Eustachius to the period on which we are now engaged, we have no work upon the anatomy of the organ of hearing equal to that of Du Verney's, and to this day it may be consulted with advantage. We likewise are indebted to the work of $\mathrm{Du}$ Verney far more than is generally acknowledged, or perhaps writers are aware of, for having given the first impulse to anything like a knowledge of aural anatomy and surgery in England; for his book, which was published in Paris in 1683, was translated into English after his death, and published in London in 1737, being thus, though a translation, the first treatise in point of time upon aural medicine or surgery in our language. This is now a work of very great scarcity, yet there can, I think, be little doubt but that Mr. Saunders availed himself largely of the labours of Du Verney. Before we take leave of this gentleman I may remark, that to him, and not to Lallemand and Itard, as I lately stated, we are indebted for the prejudice that up to this day exists with regard to the treatment of otorrhœea. But the latter are the more blameable, as they, from the age in which they lived, and the giant growth of medi- 


\section{$428 \mathrm{Mr}$. Wilde on the early History of aural Surgery, \&c.}

cal knowledge since his time, should have known better; but I believe, like many modern practitioners, they chose rather to transmit the prejudices of 150 years before, than take the trouble of investigating for themselves.

Without entering minutely into the history of aural medicine during the latter part of this, the seventeenth century, which after all would consist in the enumeration of the Latin writings of various continental authors, more curious than instructive, let us pass on to the penultimate century of our own period, and I do this the more readily, for that in it aural medicine first dawned in Great Britain. It is remarkable, that the discovery which Eustachius made, of the tube which bears his name, had no practical influence upon this branch of medicine; and that for nearly two hundred years surgery made no effort at availing itself of this improvement, for the purpose of remedying diseases of the ear. In 1724, M. Guyot, a postmaster of Versailles, proposed to the Parisiun Academy of Sciences to inject the Eustachian tube, by means of a catheter introduced through the mouth, for the removal of obstructions in that canal, and also in the middle ear. It seems, however, that the French academicians were not sufficiently aware of this valuable discovery, or at least the valuable proposal (for it is a question whether he ever performed it himself).

In the latter part of the year 1741, an English army surgeon, Archibald Cleland, published in the Philosophical Transactions an account of "instruments proposed," as he states, " to remedy some kinds of deafness, proceeding from obstructions in the external and internal auditory passages." The first of these consisted " of a convex glass, three inches in diameter, fixed in a handle, into which is lodged some wax candle, which, when lighted," he says, "will dart the collected rays of light into the bottom of the ear, or to the bottom of any cavity that can be brought into a straight line." Insignificant and incomplete as this instrument of Cleland undoubtedly was, it is, nevertheless, 
Mr. Wilde on the early History of aural Surgery, \&c. 429 deserving of our attention, inasmuch as to it may be traced the subsequent inspector auris of Deleau, of Itard, Buchanan, and Kramer. The principal object of Cleland's inspector for throwing a stream of artificial light into the meatus, was for the purpose of discovering the presence of hardened cerumen, which he removed by means of a jet of medicated steam introduced into the external meatus, but "if," says he, "this has not the desired sffect, and the person still remains deaf, the following instruments are made to open the Eustachian tube ; if upon trial it should be found to be obstructed, the passage is to be lubricated by throwing a little warm water into it, by a syringe joined to a flexible silver tube, which is introduced through the nose into the oval opening of the duct, at the posterior opening of the nares, towards the arch of the palate." These Eustachian catheters had affixed to them a sheep's nreter, to the other end of which was attached the syringe, "whereby," he says, "warm water may be injected; or they will admit to blow into the Eustachian tube, and so force the air into the barrel of the ear, and dilate the tube sufficiently for the discharge of the excrementitious matter that may be lodged there." He likewise used probes, of the same size as the catheters, to explore the Eustachian tube. Cleland was either unaware of, or disbelieved, the acconnt given by Guyot, of his having introduced an instrument into the Eustachian tube through the mouth, nineteen years before, for in his essay in the Philosophical Transactions he does not once allude to the circumstance. To him, however, is undoubtedly due the merit of having first iutroduced a catheter into the Eustachian tube through the nose, the only certain way, I believe, of performing such an operation.

Fourteen years afterwards, that is, in May, 1755, Mr. Jonathan Wathan published a more detailed essay in the Philosoplical Transactions, on "a method proposed to restore the hearing when injured from an obstruction of the tuba Eustachiana." This gentlemen, who seems to have been a good practical anatomist, as well as a dexterous surgeon, had an opvOL. XXv, No. 75 . 
$430 \mathrm{Mr}$. Wilde on the early History of aural Surgery, \&c.

portunity of making a post mortem examination in a case of deafness, wherein it was found that both Eustachian tubes were "stuffed quite full of congealed mucus." If Cleland overlooked, or was unacquainted with the proposed operation of the Versailles postmaster, Wathan seems to have completely overlooked the more recent and effectual discevery of Cleland, but in allusion to the post mortem examination to which $I$ have just referred, he says, in the commencement of his very admirable' essay, " as all these concurring circumstances strengthen me in my opinion, they likewise incited me to make trial of an operation that was sometime ago proposed to the Academy of Sciences by $M$. Guyot, but the author having never practised it, he wanted the recommendation of facts to support and enforce it, it was, therefore, rejected by them as impracticable." And in a note, he adds, that Guyot having proposed the introduction of it through the month, which is quite impossible, "Petit proposed, and that learned and skilful anatomist, Mr. John Douglas, first demonstrated the possibility of passing the probe through the nose into the Eustachian tube, and to him I freely acknowledge myself indebted for the hint." The catheter used by Mr. Wathan was not much larger than a common sized probe, and was bent a little at the end, very nearly in the same form as that used by Kramer, the distinguished Prussian aurist; and with this and a syringe, he injected and washed out the Eustachian tube and middle ear. There can be no mistake about the mode of Wathan's proceeding, for he has given a very good representation of the operation in a plate attached to his Essay in the Philosophical Transactions.

I have dwelt thus long upon the operation of the introduction of instruments into the Eustachian tube, because it formed the second, and perhaps one of the greatest epochs in the history of our art; because the merit is due to our own countryman; and because none of the English works upon aural surgery are sufficiently explicit upon this point, and many of the continental ones are altogether uninformed with regard to it. Dr. Kramer, in 
Mr. Wilde on the early History of aural Surgery, \&c. 431

his critical literary review, being still under the impression that Guyot had introduced the catheter through the mouth.

The essays of Cleland and Wathan, imperfect as they were, were decidedly the greatest addition to aural surgery made in the eighteenth century, and had the discoveries and valuable observations of these practical men been followed up in England, it is probable we would now be far in advance of our continental neighbours.

I have been long familiar with, and have frequently exhibited to many of my medical friends and pupils, a peculiar form of deafness not depending upon apparent disease in the ear, or the acoustic nerve, in which the membranum tympani has fallen in, towards the inner wall of the middle ear,- -has lost, in all probability, much of its vibratory power, and, when examined under a strong light, the handle of the malleus can be seen pressing out through it. In this affection, which, I have reason to believe, is very often mistaken for nervous deafness, we have what may be termed short hearing, from an alteration in the vibratory membrane of the ear, in like manner as we have short sightedness, or myopia, from a peculiar alteration in the curve of the cornea or transparent membrane of the eye. I find, however, upon carefully perusing the paper of Cleland,* that he had some idea of the effect which I have here described, being produced (as I have frequently known it to be) by accident. "There is," he says, "another kind of deafness, which proceeds from a violent clap of thunder, noise of a canmon, or the like. In this case it is probable that the position of the membrana tympani is altered, being forced inwards upon the small bones, and so becomes concave outwardly. In this case no vibration of sound will be communicated to the drum until the membrane has recovered its natural position." With regard to Wathan's paper, I would strongly recommend its perusal, as the cases he describes are most valuable in the diagnosis of obstruction of the Eustachian tube.

During the remaining half of the 18 th century I have little to

* See Phil. Trans, vol, xli. part ii. p. 850 . 
$432 \mathrm{Mr}$. Wilde on the early History of aural Surgery, \&c.

record; the art does not appear to have advanced a single step, either in Britain or any other part of Europe. Books and essays were written, no doubt, but their authors added little to the labours of their predecessors. The great majority of these writings emanated from the German press, as, for instance, those of Gniditsch, Wildberg, Milloradovics, Kritter, and Lentin. Of the French school may be mentioned Desmonceaux and Leschevin ; the writings of the latter will be found in the Memoirs of the Royal Academy of Surgery of Paris for 1763. Having lately had occasion to examine this dissertation, which was undoubtedly the best of its day, I am bound to say that the lavish praise bestowed upon it by the French, and the severe criticisms of the German writers, within the last few years, were alike unmerited.

Up to this period (the end of the eighteenth century) no special work upon the diseases of the ear had appeared in English print, with the exception of the translation of Du Verney in 1737, to which I have already alluded. Two English works have, it is true, been enumerated by foreign writers, but they were not written upon the diseases, properly so called, but on the congenital defects of the organs of hearing.

One of these, entitled, "Philocophus, or the deaf and dumb Man's Friend," emanated from Mr. Bulwer in 1648. It was chiefly founded on the history of the Castilian nobleman, to whom I have already alluded, as being one of the first mutes taught to understand language from the motion of the lips. The other work appeared in 1669, and was much to the same effect, being " The Elements of Speech; an Essay of Inquiry into the natural Production of Letters: with an Appendix, concerning persons that are Deaf and Dumb," by Mr. William D. Holser.

I have lately met with another work of this description, written in the year 1783, entitled, "Vox Oculis Subjecta,-a dissertation on the art of imparting speech to the natural deaf and dumb."

The members of the Medical Society of London, instituted in 1773, and composed of the physicians, surgeons, and apothecaries 
Mr. Wilde on the early History of aural Surgery, \&c. 433 of that time, were not insensible to the low condition in which aural medicine stood toward the end of the last century, and in their valuable memoirs will be found some scattered notices upon the diseases of the ear, from the pens of the president Dr. Sims, Mr. Houghton, Dr. Zeucker a Prussian, and Dr. Roslet of Ostend. Most of these papers contained post-mortem examinations of cases of deafness, a practice that, I regret to say, has not been followed up, and very much to the detriment of acoustic medicine. In Mr. Sims's essay he enters into a physiological discussion regarding the nature of the Eustachian tube ; the object of which was to shew, that while we heard all external sounds by means of, or throngh, the meatus externus, we were conscious of our own voice only through the Eustachian tube. The practical part of his paper is, however, exceedingly valuable, particularly with respect to the pressing of air through the tube into the middle ear, by closing the mouth and external nares, and then making a forced expiration; but this had been already explained by Cleland in 1741 .

At the conclusion of the last, and about the beginning of this century, aural surgery and medicine were still at a very low ebb, particularly in Great Britain. This want of real medical knowledge by the regular practitioner upon the subject of diseases of the ear was, however, soon taken advantage of, not only by professed quacks and nostrum-mongers, but by the electrical, galvanic, and magnetic doctors of that day, who corresponded to the homœopaths, hydropaths, and mesmerisers of the present. At the period to which I allude each of these chemical agents, as galvanism, magnetism, and electricity, together with the celebrated metallic tractors, were applied to the ears of persons labouring under deafness, and numerous and wonderful were the cures vaunted in the periodicals of the day, as having been effected by these remedies;-cures almost equalling those now performed on the eye by prussic acid: while secret, but never failing acoustic drops, stimulating embrocations, and the like impostures, were pawned upon the public by all those who had ingenuity and effrontery enough to make money in that 
434 Mr. Wilde on therearly History of aural Surgery, \&c.

kind of way. And here let us for a moment digress from the direct course of our subject, to answer a question that $I$ have often heard propounded-Why is it that the empyric and the pretender, either licensed or unlicensed-for in those days there are as many and as impudent quacks with, as without diplomas-why is it, we are often asked, that the charlatan frequently succeeds in practice better than the honest practitioner? By the term success, we do not mean professional success in his art, but pecuniary success in life, and esteem among those with whom money "makes the man." Now although we cannot always answer this query, nor would the same explanation be applicable to every instance, we can, however, assert one fact, which, in a great measure, contributes to the success of the quack, and it is this, - the hearty response of his patients to the lesson picked up from the showman"speak a good word to your friends outside." Let any well educated, honest practitioner, be called on to treat an urgent, and alarmingly dangerous case, where insidious death stands at the sick man's door-let him bring all the powerful acquirements of long years of patient study and observation of disease - his anatomical and pathological knowledge-an eye practised to disease, and a head stored with the sound, rational, scientific, practical principles of his art-let lim add to this the kindness of a friend, nay, often the benevolence of a benefactor-let him pass anxious days and sleepless nights watching each turn of disease in his patient, and ministering to every of the many wants that surround the bed of lingering sickness-let him do all this, and finally (under Providence) restore the patient to health and to his friends-stand, as we may say, between the living and the dead, and beckon back the approaching king of terrors, and give again to society a valuable life, and to his family the only earthly means of support-what is his reward? $\mathrm{He}$ is, generally at least, paid his fee, and the patient and his family are generous enough to say they feel grateful for all his kind attention;-for we will not curtail it of whatever good 
feeling may be shewn on the occasion. But compare this with a patient who imagines he is cured of an imaginary disease by a water doctor, or an atom doctor, a mesmeriser, or a magnetiser, is he not immediately converted into a partisan?- does he not become a missionary for the nostrum-monger?-does he not go about from house to house detailing the miracle of his cure, the skill of the doctor, the horrors of the regular practitioner, and the great benefit conferred upon mankind by being converted into hydraulic machines; or expressing his surprise that people will go about their ordinary business " clothed and in their right mind," like the man from whom the seven devils were cast out, instead of being wrapped in a wet sheet; while others will wait upon you specially, to beg and entreat you will not convert your poor stomach into an apothecary's shop by taking all that terrible doctor's stuff, instead of procuring rest and ease to all your ills, by just such an anodyne as would be formed by pouring one drop of laudanum into the Bosphorus, where it leaves the Euxine, and drinking a thimble-full of the same water where it enters the Mediterranean! But not content with this, these medical missionaries abuse all regular practitioners, and often force (for humanity's sake, as they say) the charlatan upon the patient, who then trusts to his address for future fame and profit. But to return to our text.

Several experiments had been tried by anatomists and physiologists upon dogs and other animals, in order to discover whether the function of hearing could be carried on with a perforate, or imperfect membranum tympani. These investigations upon the lower animals being deemed inconclusive, Mr. Cheselden, the father of English surgery, proposed to experiment in this matter upon the living human subject, and for this purpose a condemned criminal was pardoned, on condition of submitting to the operation! but a popular outcry prevented its being put in force!! Some years afterwards, Sir Everard Home, in his article upon the muscularity of the membrana tympani, having expressed his desire to know the result of perforation or de- 
$436 \mathrm{Mr}$. Wilde on the early History of aural Surgery, \&c.

struction of this membrane, Mr., afterwards Sir Astley Cooper, published a letter in the Philosophical Transactions for the year 1800, entitled, "Observations on the Effects which take place from the Destruction of the Membrana Tympani of the Ear." Although this paper did not advance our practical knowledge upon the subject, yet it called the attention of British surgeons to the treatment of this important organ, and put an end to a very generally received notion among the Profession, that hearing would be totally lost on the opening of the membrana tympani ; notwithstanding that a couple of hundred years ago it was believed by anatomists that an aperture existed in this structure, as a normal condition during life.

In the following year (1801) Cooper published an essay in the same work on the perforation of the membrana tympani, as a means of removing a particular species of deafness, - that caused by the obstruction of the Eustachian tube, and, according to his ideas, a consequent want of vibration in the tympanal membrane. This paper commenced a new era, and opened up a wide field in aural surgery. Like all discoveries in medicine, however, it was at the time, and in other hands, too frequently had recourse to, and often misapplied. The brilliancy of this operation, and its instantaneous, nay, in some instances, almost miraculous effects, urged men to employ it who were totally ignorant of its application, as well as of the structures and diseases of the organs of hearing generally; so that it soon fell into disuse, and although recommended by this high authority, the superior instruments we now possess of diagnosing with greater accuracy the condition of the middle ear, and its internal faucial aperture, by means of the air-douche, and also owing to the comparatively few cases of deafness solely depending on closure or stricture of the Eustachian tube, has rendered its performance much less frequently necessary than was at first supposed. This may be termed the third epoch in our art.

A few months before Sir Astley's death, I had a long conversation with him upon the subject, and to shew the interest which be took in aural diseases to the very last, I may remark, 
Mr. Wilde on the early History of aural Surgery, \&c. 437 that some little discussion having arisen regarding the subsequent condition of the perforation in the membrane, he at once sent off to Bond-street for a linen-draper, on whom he had operated some years before, in order to exhibit to me his ear, although, at the same time, from the number of persons who were desirous of consulting this great surgeon, there was scarcely room to sit down in any of his waiting apartments. This trivial circumstance, however, as all who knew Sir Astley are aware, was characteristic of the zeal and enthusiasm of the man.

Himley, Itard, and Deleau, improved and modified the instruments and the operation of Cooper. We cannot, however, conclude this notice of Sir Astley's improvement, without quoting the pertinent and judicious remarks with which he closes his memoir-advice and remarks, I regret to add, that have been but little attended to, and that are, therefore, as applicable to the present time, as they were to the period at which they were written, upwards of forty years ago.

"I hope others will be induced," he says, in alluding to the success of his operation, " to second my feeble efforts, and to direct their attention to a subject which appears to be of the highest importance, and to have been too much neglected by medical men ; for a knowledge of the structure of the ear is by no means general in the profession, and still less are its diseases understood. A prejudice has prevailed that the ear is too delicate an organ to be operated upon, or, as it is commonly expressed, tampered with; and thousands have thus remained deaf for the rest of their lives, who might have been restored to their hearing had proper assistance been early applied."

As the space allotted to an essay of this description is necessarily limited, I find I must compress the history of our art, with few exceptions, into the labours of British aurists. I have, in the preceding pages, remarked upon the condition of aural surgery about the commencement of this century, but at the same time, I am bound to say, that the well-marked inflammatory diseases of parts of the auditory apparatus, such as the auricle, voL. XXV. No. 75 . 
438 Mr. Wilde on the early History of aural Surgery, \&c.

external tube, and membrana tympani, were generally treated, by all well-educated surgeons, as in the present day, by strict antiphlogistic means, such as the local abstraction of blood, purging, and counter-irritation,-but here the judicious interference of art ceased.

First upon the list of British writers upon the acoustic apparatus and its diseases, stands John Cunningham Saunders, the distinguished oculist, and the founder of the London Infirmary for curing Diseases of the Eye, on whose merits, as an original observer, a sound practical surgeon, and a critical anatomist, I need not, to the readers of this Journal, expatiate. His work upon the anatomy and diseases of the human ear was first published in 1806, and although, as I already alluded, he availed himself of the labours of Du Verney, still to Saunders we are indebted for our first special English work upon this subject, and to him the various charlatans, that have ever ventured to set forward their ideas in print, are indebted for the mine from which they drew forth the material of their various and voluminous publications. Saunders, as an aurist, has been unjustly dealt with: he wrote, not only in accordance with, but beyond the knowledge of, his time, and Kramer not only criticises his work with too great severity, but denies it the place, which, in a chronological point of view, it deserves. This, however, is accounted for by Kramer's having quoted from, and perhaps he only had access to, the third edition, published in 1829 , just nineteen years after Mr. Saunders' deatl. The practical portion of the work consisted of the diseases of the meatus externus, and those of the tympanum, of the obstruction of the Eustachian tube, and of the diseases of the internal part of the ear, to which are added cases of incipient nervous deafness successfully treated. The plates of Mr. Saunders' work are worthy of inspection, and were evidently drawn from recent dissections.

For six or eight years we hear nothing of aural surgery in Great Britain, and our space will not permit of our even enumerating the names of the different Continental writers for the first 
Mr. Wilde on the early History of aural Surgery, \&c. 439

twenty years of the nineteenth century. The untimely death of Saunders, and Cooper's increasing, more extended, and more lucrative line of practice, seem to have cast a veil over this branch of knowledge in these kingdoms. In the years $1813-15$ and 17, we find three special works on aural medicine; of the first of these, "A Treatise on the Eye, and on some of the Diseases of the Ear," by Mr. J. Kennedy, there is little even to criticise ; the second, "Dissertatio de Aure humana et ejus Morbis," was an inaugural essay published by Mr. Ball at Edinburgh, likewise of little note; and the third was the first work of the since far-famed John Harrison Curtis. Let us read its high sounding title: "A Treatise on the Physiology and Diseases of the Ear, containing a comparative View of its Structure, Functions, and of its various Diseases, arranged according to the Anatomy of the Organ, or as they affect the external, the intermediate, and the internal Ear." Let us draw from the writings of a foreigner, who had never seen the redoubted London aurist, the opinion that a man of honesty and practical experience formed of this and his other subsequent works. "Curtis," says the writer, " treats every discharge from the ear exclusively, and in a sum. mary way, by means of astringents; obstructions of the Eustachian tube, with emetics and perforation of the membrana tympani; whilst in spite of all the entreaties of Saissy he has never once practised catheterism of the Eustachian tube on the living subject. He makes tinnitus the chief symptom of nervous deafness, which he treats with purgatives, especially calomel, as long as the strength of the patient holds out." "In all doubtful cases the chief attention is directed merely to ascertain whether the liquor cotumnii be partially or totally deficient!! or, whether hardened wax exist in the meatus." "In the otitis of children he sticks opium into the affected ear, \&c., so that throughont all his writings, nothing but the most crude empiricism is to be met with; and yet among his compatriots, as well as abroad, Curtis generally possesses the reputation of being a distinguished aurist." And one of the first English medical periodicals of the day thus ex- 
$440 \mathrm{Mr}$. Wilde on the early History of aural Surgery, \&c.

presses its admiration of the same person : "Mr. Curtis, in his treatise on the physiology and pathology of the ear, has appropriated the whole of Mr. Saunders' essay. The exact words, indeed, have, in some instances, been changed, but the plagiarism is too manifest to escape even the most inattentive reader. To this paraphrase of Mr. S.'s work, Mr. Curtis has added some things from other authors, and some histories of cases treated by himself (of course all most successfully), and has thus concocted a treatise, which, with singular effrontery, he has put forth as entirely of his own composition, and as containing the results of his own practice. This work has now, for a period of about twenty years, been forced upon the attention of the public, by the advertisement of successive editions; and it is a melancholy fact, that there should have been found editors of medical journals either so ignorant or so careless, as to lavish commendation on such a production." Almost in a similar category may be classed the writings of Williams, surnamed the nostrum-monger, and also those of Stephenson and Wright. The latter followed something of the plan laid down by Curtis, of simply recomposing the words of his first work ; for as to new ideas, there were none, nor old ones to aadd them to. In order to form either a new edition, or a new book, we find the changes rung to the following tunes for about ten or "eleven years: "An Essay on the human Ear, its anatomical Structure, and incidental Complaints, 1819 ;" "The Aurist, or medical Guide for the Deaf, 1825 ;" "Plain Advice for all Classes of deaf Persons, the Deaf and the Dumb, and those having Diseases of the Ear, 1826,"-verily this must have been a:popular book. "On the Varieties of Deafness and Diseases of the Ear, with proposed Methods of relieving them, 1829 ;" "Observations on the Effects of Mercury on the Organs of Hearing, and the improper Use of it in Cases of nervous Deafness, 1827." To this was added, "The present State of aural Surgery," together with three or four others, all by the redoubted Mr. William Wright. To these productions may be added those of Webster, Thornton, and Fletcher ; works simi- 
Mr. Wilde on the early History of aural Surgery, \&c. 441

lar in substance and composition, although, perhaps, not so flagrant in plagiarism. There is one English work that we would rescue from the criticism which has been already applied to its predecessors. In 1823, Mr. Thomas Buchanan, an intelligent surgeon of Hull, published an engraved representation of the anatomy of the human ear, to which were added some surgical remarks upon Eustachian catheterism, together with an acconnt of the operation of puncturing the membrana tympani, and concluding with a synoptical table of the diseases of the ear. Mr. Buchanan no doubt put forward many fallacies in his work, particularly his ideas with regard to the physiological uses and diseases of the external meatus, but in a literary point of view we may remark, that he seems to have fallen into the snare almost peculiar to English aurists, for within a couple of years he followed up whatever success may have attended his first publication, by producing two other works, one the "Illustrations of," and the other, "The Guide to, acoustic Surgery "" and in 1828 appeared a fourth work, "Physiological Illustrations of the. Organs of Hearing, more particularly of the Secretion of Cerumen, and its Effects in rendering auditory Perception accurate and acute." Buchanan, however, deserves our commendation and commands our respect, as being the first English writer who, since the days of Saunders and of Cooper, based his works upon a knowledge of the principles of anatomy and surgery ;-and to him we are indebted for the second, in point of time, improvement in the inspector auris, by means of which, as I have already explained elsewhere, artificial light was transmitted through the meatus on the membrana tympani.

About this time (1820) some notices of aural diseases appeared in the medical periodicals of this country, and foremost among the writers of these stands Mr. Henry Earle, whose short, but accurate and practical observations upon some diseases of the external meatus, published in the London MedicoChirurgical Transactions, are well worthy of perusal; and the Lancet and Medical Gazette likewise contain some detached 


\section{Mr. Wilde on the early History of aural Surgery, \&c.}

notices, and the details and pathological appearances of several cases of the diseases of the organs of hearing.

Within the last twelve years there have appeared three small works upon the anatomy and physiology of the organ of hearing, by Mr. Swann, Mr. David Todd, and Mr. Caswall. The first of these little works, from the originality of its ideas, and the speculative theory of its author, justly attracted attention in an anatomico-physiological point of view, yet neither it nor the other two with which it is associated should have been enumerated in an essay upon the history of aural surgery, but that to each were affixed some observations upon the pathology generally, and the congenital defects in particular, of this particular organ of sense. These observations, however, are as crude and unpractical as they are speculative and unfounded. I may merely mention one of these as a sample of the rest: Mr. Todd proposes as a remedy for congenital deafness depending on derangement of the structures in the tympanum, the introduction of such acrid substances as ammonia, cantharides, and the mineral acids, in order to produce such an inflammation as may rouse into activity the dormant powers of the parts contained within that cavity!

Here we leave English aural surgery for the present, that is about the year 1830, and first let us visit our Gallic neighbours. The splendid discoveries of Laennec with regard to the stethoscope, and the morbid or abnormal sounds produced by streams of air passing through or over diseased structures, were not long in being laid hold of as a means of diagnosis by those of his countrymen who had devoted their talents and energies to the investigation and treatment of diseases of the ear. Foremost among these stood Deleau, and next to him Itard; the works of the former were the first to introduce into general practice in Europe the introduction of various medicated vapours, as well as fluid injections, into the middle ear, by means of catheterism of the Eustachian tube, a practice since so successfully employed by Dr. Kramer of Berlin. But it should not be forgotten that si- 
Mr. Wilde on the early History of aural Surgery, \&.c. 443 milar means were employed in England nearly a hundred years ago by Cleland and Wathan. The labours of Itard are principally worthy of support, from the clearness and perspicuity of his views, and from his vast experience in treating the inflammatory diseases of the external and middle ears, yet his work is by no means devoid of those prejudices and nonsensical superstitions which, even to the present day, like the amulets of a by-past age, still hang upon or surround the works of aural surgeons.

We now pass over a long lapse of years, owing as much to the brevity necessary in this paper, as to the paucity of writers in that period, and turn again to Germany, where we find aural surgery in the highest condition of any country in Europe. As the space allotted to an article of this description is necessarily limited, I must compress my observations within the limits of two works, those of Lincke and Kramer. The former never having been translated into the language of this country, few of my readers can have had an opportunity of being acquainted with its merits; I shall only say for it, that although it contains but few original observations, and is, perhaps, rather prolix in its literary analysis, yet it comprises all that was known upon the subject of aural surgery at the time in which it was written, in 1840. Another industrious compiler is Doctor Schmalz of Dresden, whose work on the Deaf and Dumb is one of the very best in print. To Doctor Kramer of Berlin we are inindebted for the best treatise that has yet appeared upon this intricate and hitherto neglected branch of the healing art. I rejoice to say his work has been translated into English, and although I differ from him in his classification, and also on some pathological questions, still I am bound to say it is the best work upon the subject which it professes to teach, which has yet appeared in British print. Independent of the general value and truthful observation of this work, it also put forward some important discoveries in acoustic medicine. One of these is that of the air-press, for the purpose of more accurately intro- 


\section{$444 \mathrm{Mr}$. Wilde on the early History of aural Surgery, \&c.}

ducing atmospheric air through the Eustachian tube into the middle ear, and also the introduction of certain gaseous substances, as, for instance, the vapour of æther into the middle ear for the removal of one of the most incurable maladies-nerrous deafuess. As a means of diagnosing the condition of the tube and middle ear, it is, and ever will be, highly valuable, nay, in many cases it is indispensable; but I must confess, that although I have used it very extensively for the last three years, I have not had experience of the same beneficial results from the introduction of ætherous vapour, as the tuition, or the work of my friend led me to expect; in fact the cases in which it is applicable are comparatively very rare.

Kramer's discoveries, and his most scientific work, seem to have excited a new taste for aural surgery in Great Britain; and well educated surgeons and honest men have at last come forward to rescue this branch of the healing art from the hands of quacks and charlatans. The names of Mr. Pilcher, Mr. Wharton Jones, Mr. Toynbee, and Mr. Williams, are now a sufficient guarantee that the empiric and the nostrum-monger will soon be driven from the field. And yet that many of those latter still drive a thriving trade, may be learned from the puffs and praises bestowed upon them in several of the literary periodicals of the day. In one of these, which, from our own knowledge of the honour and integrity of its editors, as well as its hitherto stern and uncompromising stand against quackery of every description, and its high reputation for honesty of purpose and substantial literary merit, we really expected better things, it is not only asserted, but endeavoured to be proved, that by dropping "an alkaloid" into the external meatus, or rubbing the surface of the membrana tympani with it, persons born deaf and dumb have been almost instantaneously cured ! nay, not only is hearing restored on the moment, but the miracle (for miracle it certainly is, if true) extends to the organs of speech also, as in one case, and that too given on the faith of a medical man, and conveyed in a letter to the operator; he says, that "after 
Mr. Wilde on the early History of aural Surgery, \&c. 445

repeated examinations of many of the objects under your care, previously to any thing being done, I satisfied myself that they were both deaf and dumb. I have witnessed the application of your remedy to the ears, and bear testimony to them having in my presence obtained the sense of hearing." But-miracle upon miracle-the faculty of speech to one who had never heard the sweet sounds of a human voice, follows almost as matter of course; for, adds the narrator, " and by my own tuition, in $a$ few minutes afterwards acquired the power of speech!" Query -was it broad Scotch they spoke?

It is always a matter of difficulty to argue on a medical or legal subject with a non-professional person, for it is quite impossible (especially with respect to medicine) for a person uninstructed in anatomy and physiology, medicine and surgery, $\& c$., to be convinced of his error, any more than it is for him to form an opinion of the merits of a cure or the causes of a failure. How few students, after two or even three years' study in the preparatory and elementary courses, would be capable of estimating the value of any medical production put into their hands, and yet " in order to ascertain in what respects Doctor Turnbull's practice differed from that which is general in the profession," we are gravely informed by the editors of the Edinburgh Journal, that they "studied the most recent and approved works on aural surgery." Such discussions with nonmedical persons should be avoided as much as possible, they tend to no good, and were it not our conviction that Mr. Chambers, for whom we entertain the highest respect, has been made the dupe of Dr. Turnbull, we would not have alluded to the subject. Had the Editor known anything of the structure of the parts he is attempting to describe, he would have been better informed than to publish an account of an analogy between the ceruminous glands in the external meatus, and the mammary gland in the female; for in the article to which we allude he says: "Finding cured persons relapse in conséquence vol. Xxv. No. 75 .

$3 \mathrm{M}$ 
$446 \mathrm{Mr}$. Wilde on the early History of aural Surgery, \&o.

of the defect of wax, Dr. Turnbull was prompted to use his ingenuity in endeavouring to discover a means of sustaining that secretion. He reflected that the application of the month of the child to its mother's breast, by removing the pressure of the atmosphere, causes the milk immediately to flow, and he conceived that a similar result might follow with respect to the wax of the ears, if he could by any means remove the pressure of the atmosphere from the external parts. For this purpose, he at first used a syringe with an Indian rubber mouth exactly fitted to the aperture of the ear." Now the veriest tyro in medicine knows that it does not depend on any atmospheric pressure, but is owing to a morbid action in these follicles themselves that the ear-wax is not secreted. In fact they are, if there be any analogy at all in the case, in something of the same condition that the flow of milk, and the mammary gland are in, in females not giving suck. But as we fear we would not be understood, we cannot stop to explain to this non-medical editor the difference between the funtcions and processes of secretion and excretion. Would any other but a non-medical person be absurd enough to suppose that the application of an exhauster to the nipple would produce a secretion of milk : or cause a flow of milk, unless such had been already secreted in the lactiferous tubes? But yet we read-." the plan was successful ;" and the reason assigned is, because "the blood-vessels resumed a free circulation, and the flow of wax recommenced."

Again, we learn that "the clearing of the Eustachian tube, for which no means formerly existed but the application of medicine to the bowels, or the dangerous use of a catheter, was affected by Dr. Turnbull by the same simple means." Well may the friends and admirers of the Russell-square professor employ the term dangerous, for the only record of any accident or ill effect having arisen from the employment of this exceedingly simple and harmless operation, occurred to Dr. Turnbull himself, two of whose patients, in the year 1839 , fell victims to 
Mr. Wilde on the early History of aural Surgery, \&c. 447

the operation of catheterism of the Eustachian tube, and on both of whom coroner's inquests were held. One of these, it appeared in evidence, was, almost immediately after the operation, attacked with emphysema of the throat and inflammation of the brain, of which he died in a week; and the other, a lad, named Joseph Hall, aged 18, and in perfect health, "fell back in the chair apparently lifeless, and never spoke afterwards."* In the first of these cases it appears most likely that the emphysema was caused by the instrument rupturing and tearing the mucous membrane; and in the second, in all probability, the death was caused by the shock or concussion given to the base of the skull by the volume of compressed air,-for where the mouth of the catheter was we know not. After this it seems the Doctor changed his hand, and finding that it was rather a "dangerous" experiment to " blow up" his patients, determined to suck them as much as possible; and, in order to effect this, Mr. Chambers informs us, that by means of an air-pump, in connexion with a small glass tube, " introduced into the mouth of the patient," and consequently behind and above the soft palate! "and applied to the orifice of the Eustachian passage, communication is opened between the previously rarified air in the receiver and the orifice, from which a discharge of mucus is soon made into the tube, which is then withdrawn." But we cannot discuss further those matters with a person who speaks of the "vibrations of the tympanum !" With one word more let us dismiss this subject of Dr. Turnbull and his review ; - a word worthy of consideration to those who may be induced by the articlet, to which we allude, to submit their deaf mute friends or relatives to useless pain and profitless experiment. It is this:Were the miraculous cures of the Saviour performed on cases or diseases that art, either then or now, could have remedied?could remedial agents, or man's interference, have raised the

- Lancet, July 6, 1839.

† See Chambers' Journal, No. 519. 


\section{$448 \mathrm{Mr}$. Wilde on the early History of aural Surgery, \&c.}

dead-thrown instantaneously the vigour of youth, and the health and strength of manhood, into the limbs of the cripple-given power to the parylitic-steadiness to the palsied-and calmness to the possessed; or have cooled the fevered_given sight to the blind - speech to the dumb, and hearing to the deaf?-If, without the special interference of Providence, these individuals could have been cured, then, in my humble opinion, they were not miraracles; but if without the pale of art, or beyond the power of human means, then were they miracles, and cannot now be performed but by similar means. That, however, the age of miracles is again at hand, Mr. Chambers appears to have some idea, for, no doubt aware of the instantaneous restoration of speech and hearing to the deaf mute being one of the miracles assigned to Christ, he concludes by saying: " "Every thing but trodden ont of existence,' is, in one word, the fate of the individual who has been the first merely human being to cause the deaf to hear." But why discuss a question arising out of an assertion as to the possibility of perfectly and instantaneously restoring to speech and hearing the congenital deaf mute, which all soberminded men in the community, save and except the Doctor and his reviewers, deny?

Let us, in conclusion, inquire what the legitimate aural practitioner in the present day is, and how far his art extends over the regions of disease. First, a practitioner in aural surgery, or, if it pleases the public to call him an Aurist, in our day must, or at least ought to be, in the first instance, a welleducatedj surgeon and physician, instructed in anatomy, physiology, chemistry, materia medica, and the other elementary branches of the healing art, who applies the recognized principles of medicine and surgery to the diseases and abnormal conditions of the organs of hearing, in the same manner as the modern ophthalmic surgeon does to the diseases of the eye. With regard to the second proposition, of how far our art extends over the regions of disease-we daily hear and read, and 
Mr. Wilde on the early History of aural Surgery, \&c. 449

it has been reiterated from mouth to mouth, and copied from work to work, that the treatment of diseases of the ear is an opprobrium to the healing art, and without the pale of human knowledge. To this objection against our art it may fairly be urged, that notwithstanding the injudicious treatment prescribed by quacks and nostrum-mongers; and, as in many instances, we know it is, the total abandonment of all treatment by the general practitioner, still were the statistics of all our diseases carefully collected, it would be found that there were among them as many curable cases of affections of the ear, as there are among the severer maladies of the eye, or among diseases of the chest, the brain, the liver, or any other organ, the treatment of which falls to the lot of either the physician or surgeon. It must, however, be admitted, that up to a very recent period, this question of - "what can you do for deafness?" might have been asked with great justice, because, from the circumstance of well-educated medical men in this country either considering it beneath their station or acquirements to treat so insignificant an organ specially, or not finding in the direct cultivation of aural surgery a sufficient remuneration for their time and talents, this branch of the healing art has remained in that state in which ophthalmic surgery was half a century ago-in the hands of charlatans and mountebanks. All this, added to the smaller share of sympathy afforded to the deaf than the blind, and to the circumstance of impairment of hearing interfering less with man's means of subsistence, and also to the fact that it is much more easy to pawn cures of deafness than cures of blindness upon the general public; besides the greater difficulty of minutely examining, either during life or after death, the accurate condition of, or the morbid changes which occur in the middle and internal ear, serve to account for why aural pathology and aural surgery have not kept pace with the other rapid improvements in medical science, and why so few works worth reading have been as yet written on the subject. Above all, the well-instructed 
$450 \mathrm{Mr}$. Wilde on the early History of aural Surgery, \&c.

aurist of our time possesses a knowledge and a power which is not general among the Profession-of making an accurate diagnosis, which, when given with honesty, will frequently save the patient much anxiety, loss of time and money, and often much unnecessary suffering.

I offer the accompanying nosological arrangement of diseases of the ear, defective as $I$ know it is, more for the purpose of eliciting inquiry, and as a basis for future investigations, than as possessing any great merit of its own.

To the difficulties attending all synoptical arrangements, we have here to encounter additional ones, arising from the obscurity of the parts affected, and the absence of definite pathological knowledge with regard to many of the diseases of the organs of hearing. And whether we attempt a classification, according to the symptoms, as the means employed by Cullen and Mason Good,--or whether it is based upon the pathology and morbid anatomy of the tissues affected, as made use of by our modern nosologists, the same difficulties beset us.

The first chart of aural diseases worth mentioning is that arranged by Galen. It consists of five affections, viz. : otalgia, baruckoia, kophotis, parakousis, and parakousmata; but these it is perfectly evident, were but symptoms, not diseases, and to these he added, pain in the ear from cold, inflammation, and "ex fatulento spiritu aut crassis et viscosis humoribus est ex serosis et saniosis humoribus."

The first attempt at an arranged nomenclature of aural diseases in Great Britain was that by Buchanan in 1825, who, in his "Illustrations of acoustic Surgery," endeavoured to classify those affections according to the parts affected, but his diseases are mere symptoms. It consists of three orders, twelve genera, and thirty-three varieties; that, however, this division is most imperfect, nay, in some respects positively absurd, may be learned by an examination of his fourth genus alone, styled, "Impedimentum Externum," or obstruction of the external meatus, under which 
Mr. Wilde on the early History of aural Surgery, \&c. 451

he enumerates four species, each resulting from causes totally different, and quite unconnected with one another, viz.: " $\mathrm{Im}$ pedimentum Extraneum, from extraneous substances; Impedimentum Induratum, from indurated wax; Impedimentum Polyposum, from polypi ; and Impedimentum Excrescens, from excrescences!"

Kramer seems to follow this classification in some respects, in his division of the diseases of the external, middle, and internal ear; but this method had been long before attempted by Dı Verney. Kramer makes seven sections, viz.: diseases of the auricle, of the external meatus, and of the membrana tympani ; inflammation of the mucous membrane, of the cellular tissue, and periosteum of the middle ear; and two forms of nervous deafness, the erethitic and the torpid. The inflammations, which are those diseases on which his work principally treats, he divides into those affecting the various tissues, as the cellular, the mucous, and the fibrous; but there are many, and very formidable diseases too, on which he is perfectly silent.

Mr. Wharton Jones's arrangement* is entirely an anatomical one, consisting of two parts, viz.: the diseases of the accessory organs of the apparatus of hearing, - and the diseases of the fundamental organ of hearing, ear-bulb, or labyrinth, with the minute sub-divisions of both these portions.

Mr. Williams does not attempt any classification whatever, and Mr. Pilcher's work is likewise defective in this respect; his arrangement, if such it can be termed, being a simple enumeration of aural affections, divided into, the abnormal conditions or malformations; otitis, or acute inflammations; chronic diseases of the ear; and nerrous diseases of the ear.

Lincke is by far the best modern classifier; he makes three divisions-first, inflammations of the organs of hearing; second, affections caused by solution of continuity; and third, affections

"See Article "Ear and Hearing, Diseases of," in the Cyclopædia of Surgery, part ix. 
$452 \mathrm{Mr}$. Wilde on the early History of aural Surgery, \&c.

caused by cohesion of parts; but he does not classify the diseases of the sentient portion of the auditory apparatus, ar nervous deafness. We hope to see a third volume from this anthor on these most obscure forms of disease.

I have retained the original terms in order to preserve a tabular arrangement which I have here allempted. His first division contains two sections, the simple and the complicated, and the former is again subdivided according to the locality, as:

\section{FIRST DIVISION.}

Inflammations of the Organs of Hearing.

SEC. I.-Simple. SEC. II-Complicated and specific.

Outer Ear. "Attritus Auriculæ. Otitis, Erysipelatosa.

Erythema Auriculæ.

" Catarrhalis.

Inflammatio Auricula Phleg- " Gonorrhoica. monosa.

"Rheumatica.

Pernio Auricule, a frigore.

Inflammatio Meatus AudiArthritica, s. Otagra. torii.

Inflammatio Membrana Tympani (Myringitis).

Middle Ear, Otitis Universalis $\mathrm{s}$, interna totalis.

Inflammatio Tuba Eustachianæ (Syringitis). Scrophulosa. Syphilitica. Morbillosa.

" Scarlatinosa.

"Variologr.

" Eczematica s. Crusta Lactea.

" Herpetica.

\section{SECOND DIVISION.}

Affections caused by Solutions of Continuity.

"Contusio Auriculæ.

Vulnera Auriculæ.

Fractura Auriculæ.

Vulnera Membrana Tympani.

Vuinera Totalis Auris.

Coloboma Auriculæ.

Foramina Membranæ Tympani. 
Mr. Wilde on the early History of aural Surgery, \&c. 453

THIRD DIVISION.

Affections caused by Cohesion of Parts.

"Dilatatio Meatus Auditorii.

Structura Meatus Auditorii.

Compressio s. Thlipsis Meat. Aud.

Collapsus Meatus Auditorii.

Atresia s. Obliteratio Meat. Aud.

Dilatatio tubæ Eustachii.

Strictura tubæ Eustachii.

Obturatio tubæ Eustachii.

Collapsus tubæ Eustachii.

Obliteratio tubre Eustachii.

Imperforatio tubæ Eustachii.

Aneurisma et Varix Auriculæ.

Cirsomyringa."*

I am indebted to this enumeration of Lincke's for the first account of some of the diseases I have introduced into the accompanying Nosological Table; yet, with few exceptions, they have all passed under my own observation, and I have not admitted any but upon my own personal knowledge, or on authority of undoubted veracity. To enter minutely into the description of this chart, or the position given to each disease in it, would be trenching on a subject not intended to be included in this essay. In fact it explains itself. The nomenclature, as far as it was possible, has been reduced to English, except in such terms as " hypertrophy" and " nævus," \&c. The term Myringitis is employed to signify inflammation of the external layer of the membrana tympani, and is therefore placed among the affections of the external meatus. The description of the rarer forms of aural disease, as those now, for the first time, brought before the professional public, I must reserve for another opportunity.

* Handbuch der theoretischen und practischen Ohrenheilkunde, - von Dr. Carl Gustav Lincke. Zueiter Band. Die Nosologie und Therapie der Ohrenkrankheiten. Leipzig, 1840.

voL. $\mathrm{XxV}$. No. 75 . 
$454 \mathrm{Mr}$. Wilde on the early History of aural Surgery, \&c.

It may appear strange that tinnitus aurium, or noise in the ear, is not enumerated among the affections specified in this classification; but I have long since convinced myself that it is but a symptom, and not a special disease; and so variable an attendant is it, that like musca volitantes in the eye, which it very much resembles, we cannot, as yet, accurately determine what are the particular morbid states which is symptomatic of it, or accompanies. The value of tinnitus aurium, as a means of diagnosing diseases of the brain and diseases of the ear, as well as the peculiarity of the sensations accompanying certain morbid conditions of these organs, would form a very valuable addition to our pathological knowledge. 